\title{
ERRATUM
}

\section{Early versus late start of open kinetic chain quadriceps exercises after ACL reconstruction with patellar tendon or hamstring grafts: a prospective randomized outcome study}

\author{
Annette Heijne $\cdot$ Suzanne Werner
}

Published online: 17 March 2007

(C) Springer-Verlag 2007

\section{Erratum to: Knee Surg Sports Traumatol Arthrosc} DOI 10.1007/s00167-006-0246-z

Unfortunately, Figs. 2 and 3 were published without the explanations of the $P$ values. Therefore, both figures and legends are given here again with the explanations included.

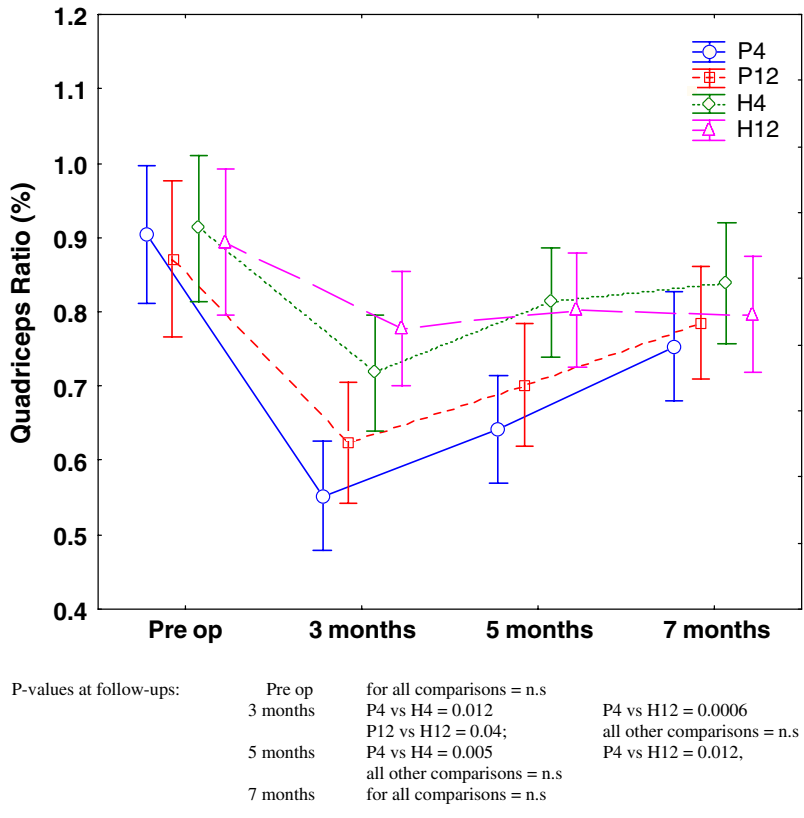

Fig. 2 Quadriceps muscle ratio (reconstructed knee/asymptomatic knee) (mean and CI) preoperative at 3,5 and 7 months follow-up for the P4, P12, H4 and H12 groups
The online version of the original article can be found at http://dx.doi.org/10.1007/s00167-006-0246-z.

\section{A. Heijne $(\square) \cdot S$. Werner}

Section of Orthopaedics and Sports Medicine,

Department of Molecular Medicine and Surgery,

Karolinska Institutet, 17176 Stockholm, Sweden

e-mail: annette.heijne@ki.se

\section{S. Werner}

Capio Artro Clinic,

Stockholm Sports Trauma Research Center,

Karolinska Institutet, Stockholm, Sweden 


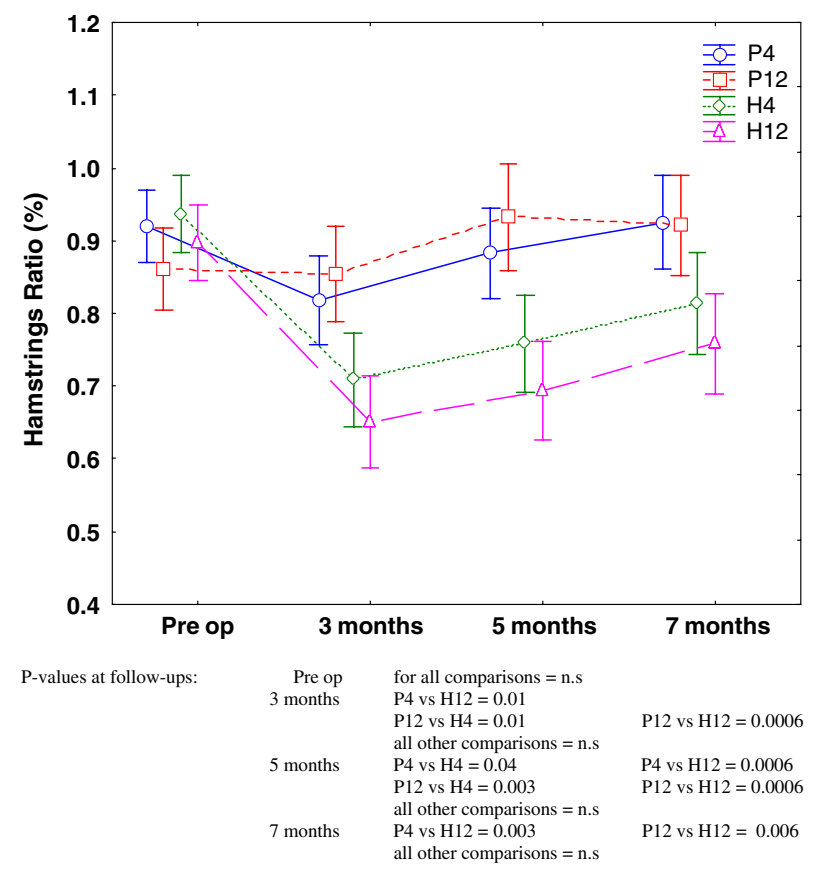

Fig. 3 Hamstring muscle ratio (reconstructed knee/asymptomatic knee) (mean and CI) preoperative at 3, 5 and 7 months follow-up for the P4, P12, H4 and H12 groups 